National survey of commissioners' and service planners' views of public health nursing in the UK

\title{
Authors:
}

Nigel Davies ${ }^{\mathrm{a}, *}$

MSc, RN

${ }^{a}$ Faculty of Health and Social Sciences, University of Bedfordshire, Luton, UK. nigel.davies@beds.ac.uk

Helen Donovan ${ }^{b, c}$

MEd, RN

${ }^{\mathrm{b}}$ Royal College of Nursing, London, UK

c Barnet Clinical Commissioning Group, London, UK

helen.donovan@rcn.org.uk

* Address for correspondence:

Prof. Nigel Davies

Faculty of Health and Social Sciences

University of Bedfordshire

Room 116, Putteridge Bury Campus

Hitchin Road

Luton

Bedfordshire, LU2 8LE

T: 01582489082

M: 07813608585

E: nigel.davies@beds.ac.uk 


\section{National survey of commissioners' and service planners' views of public health nursing in the UK}

\section{Introduction}

Improving public health is a key policy area both in the United Kingdom (UK) and internationally. The governments across the four UK countries each have specific strategies to guide improvements in public health services, promote greater emphasis on how people can best be helped to live healthier lives and to help address the unprecedented challenges of both an increasing population and financial austerity.

Nurses are often ideally suited and uniquely placed to respond to public health challenges as they understand the particular risks of individuals but also know the population and the communities they work in ${ }^{1}$. Traditionally in the UK public health nurses have been seen as those in specialist community roles such as health visitors, school nurses and occupational health nurses and in some cases specialist practitioners. However, there is an increasing need for all nurses to embrace the contribution they can have to make every contact count.

During 2015 the Royal College of Nursing in the UK (RCN) undertook a programme of work building on a previous project ${ }^{2}$ to showcase public health nursing (see www.nurses4PH.org.uk). As part of this wider RCN programme, a survey was conducted to explore the views of commissioners and others involved in designing and planning public health services about the nursing and midwifery contribution to public health. The aims were to explore the perceived value of nursing in public health, to better understand the roles of nurses and midwives in public health, how these roles were valued, and what and where the gaps were in public health nursing knowledge and education.

\section{The survey}

A national web-based survey of commissioners, service planners and practitioners of public health services was undertaken in May 2015. The survey was developed specifically for this study and was restricted to 23 questions to ensure ease of response. The first five questions of the survey elicited demographic data. The main section was divided into three areas reflecting the elements of public health defined by the UK Faculty of Public Health ${ }^{3}$ and used a Likert scale to elicit respondents' opinions of:

- the frequency of nurses actual involvement in public health services; 
- how much involvement respondents thought nurses should have;

- the reasons respondents employed nurses in public health services;

- the skills nurses bring to this involvement;

- the quality of the nursing contribution; and

- whether respondents were satisfied with the skills, knowledge and experience of nurses.

Finally, three open ended questions asked respondents to provide information on challenges to commissioning care with public health interventions, skills looked for when designing public health services with nursing teams, and the extent to which patient or care pathways included specific indicators for public health. The questionnaire was reviewed by an expert advisory panel to ensure face validity.

A snowball sampling method was used to reach networks and suggested contacts. The survey invitation was sent to a large targeted population using the RCN database and a specific list identified by the authors. Additionally, NHS England also advertised the link to the survey in their weekly Clinical Commissioning Group (CCG) bulletin. This approach helped reduce the risk of missing potentially relevant respondents.

Four hundred and ten people accessed the survey from across the UK. Almost half of these $(n=191)$ were filtered out at the first questions because they were not directly involved with commissioning or designing services. Consequently, the responses from 219 people completing the survey were included in the analysis. Ninety per cent of responses came from people in England and included a broad range of NHS and non-NHS organisations.

\section{Is nursing involvement in public health hidden?}

The public health areas that respondents most frequently perceived nurses to be 'always' or 'often' involved in were mostly associated with the domain "improving services" with nurses' roles in clinical governance and clinical effectiveness featuring strongly (see Table 1). In contrast, there appeared to be least involvement associated with some aspects of the "health protection" domain suggesting this is either an area for greater investment or an example of where public health nursing may be invisible.

The perceptions of commissioners of less involvement by nurses in some aspects of public health ran counter to professional knowledge about these areas, and therefore led to an emerging theme of 
aspects of nursing involvement being hidden or invisible. This concept has been described before in North America ${ }^{4}$, Australia $^{5}$ and in Europe ${ }^{6,7}$. This continuing theme internationally where significant aspects of what public health nurses do is underestimated suggests that these activities need to be articulated by nurses and leaders to ensure those commissioning services and providers managing capacity understand the impact of any proposed service changes.

In all areas respondents believed nurses should be involved in public health more than they currently are. There were differences of over forty percentage points between actual and desired involvement in six areas (housing, employment, chemicals and poisons, radiation, emergency response, environment hazards) and a notable difference of 37 percentage points in the commissioning category. This desire by commissioners of services that nursing should be involved in more aspects of public health suggests either a gap between demand and supply, or an unrealistic expectation for nurses to be involved in areas outside their traditional preparation and scope. Alternatively, it may be that not all nurses are working to their full scope and that their potential is not being maximised because of workload issues ${ }^{8}$.

\section{Knowledge and skills}

With regard to nurses skills and knowledge there was a mixed picture with areas of high satisfaction found in all three public health domains (for example, more than two-thirds of respondents were satisfied or very satisfied with nurses skills related to domains of family and community, lifestyles, clinical effectiveness, clinical governance, and infectious diseases). However, at least a third of respondents were dissatisfied in the areas of commissioning (38\%), housing and homelessness (35\%), and employment (33\%). The perceived quality of the nursing contribution and satisfaction with knowledge and skills could be seen across all domains with respondents still believing nursing should be involved in those areas rated lower for quality.

Respondents were also asked the reasons they accessed or employed nurses in public health services and what skills they looked for in nurses. The reasons that received the highest response rates were because nurses were seen as care specialists (69\% of respondents), because of their competence (55\%), local knowledge (46\%), communication skills (44\%) and contribution to commissioning (43\%). Other personal qualities and competences also came out strongly including project and research management skills and behavioural characteristics, for example, care, compassion, determination, motivation and commitment. 
Issues were raised related to the depth of knowledge required by nurses taking on specialist public health roles and the need for advanced assessment skills to enable "every contact to count". Challenges with nurse education were identified with a perception that public health is not integrated into pre- or post-registration programmes leading to a lack of skilled staff. In relation to commissioning, respondents felt that there was a shortage of nurses in commissioning roles and a lack of understanding of specialist roles both in terms of the potential for nursing input not always being realised.

It appears that the mixed satisfaction is to some extent sector-specific or speciality related. Further exploration is needed to clarify how best to fill the gaps in knowledge and skills whilst recognising the added value public health nurses bring for employers in terms of transferrable skills such as local knowledge and communication skills. This may signify the level of importance and centrality of the nursing contribution to public health and the necessity to match this with increased investment in knowledge and skills in targeted areas. In light of the Shape of Caring Review ${ }^{9}$ the findings suggest further exploration is needed to clarify how best to fill these gaps with further discussion needed to understand which practitioners best fulfil the needs of commissioners in these areas.

\section{Conclusion}

The survey has raised a number of interesting points that can guide thinking in relation to the value of public health nursing. By targeting and questioning a defined population of commissioners and service planners about nursing the survey has been able to highlight specific areas which may not have materialised from professional or clinical debate. Against the backdrop of recent changes to commissioning and on-going change in terms of the organisation of public health services this survey highlights the value that nurses can offer. This work complements and adds to both the Public Health England work to develop a public health skills and knowledge framework ${ }^{10}$ and to the 'Shape of Caring' Review ${ }^{9}$ which identified the need for nurses to develop public health skills and competence across all areas of practice. 


\section{REFERENCES}

1. Donovan H. Pushing the boundaries (Editorial). Prim Heal Care. 2015;25(5):5.

2. RCN. Going upstream: nursing's contribution to public health. London: Royal College of Nursing , UK; 2012.

3. Faculty of Public Health. What is public health? [Internet]. 2015 [cited 2015 Oct 15]. Available from: http://www.fph.org.uk/what_is_public_health

4. Schaffer MA, Keller LO, Reckinger D. Public Health Nursing Activities: Visible or Invisible? Public Health Nurs. 2015 Mar 26;32(6):711-20.

5. Keleher H. Public health nursing in Australia - historically invisible. Int Hist Nurs J [Internet]. 2003;7(3):50-5. Available from: http://www.ncbi.nlm.nih.gov/pubmed/12710382

6. Clancy A. A profession under threat? An exploratory case study of changes in Norwegian public health nursing. Int Nurs Rev. 2007;54(2):197-203.

7. Philibin CAN, Griffiths C, Byrne G, Horan P, Brady A-M, Begley C. The role of the public health nurse in a changing society. J Adv Nurs. 2010;66(4):743-52.

8. Bungay $\mathrm{V}$, Masaro $\mathrm{CL}$, Gilbert M. Examining the scope of public health nursing practice in sexually transmitted infection prevention and management: what do nurses do? J Clin Nurs. 2014;23(21-22):3274-85.

9. Willis P. Raising the Bar - Shape of Caring: A Review of the Future Education and Training of Registered Nurses and Care Assistants. London; 2015.

10. Public Health England. Review of the Public Health Skills and Knowledge Framework (PHSKF). London; 2015. 
Table 1: Frequency of respondents' positive ratings of actual and desired nursing involvement, quality of nursing contribution and knowledge and skills for each public health domain

\begin{tabular}{|c|c|c|c|c|c|}
\hline DOMAIN (UK Faculty of Public Health ${ }^{3}$ ) & $\begin{array}{c}\text { \% rating nurses } \\
\text { actual involvement } \\
\text { as "Always" or } \\
\text { "Often" }\end{array}$ & $\begin{array}{l}\text { \% rating nurses } \\
\text { should be involved } \\
\text { as "Always" or } \\
\text { "Often" }\end{array}$ & $\begin{array}{c}\text { Difference } \\
\text { between desired and } \\
\text { actual involvement } \\
\text { ratings }\end{array}$ & $\begin{array}{l}\% \text { rating the } \\
\text { quality of nursing } \\
\text { as "Consistently" or } \\
\text { "mostly high" }\end{array}$ & $\begin{array}{c}\% \text { rating } \\
\text { skills and knowledge } \\
\text { as "Satisfied" or } \\
\text { "very satisfied" }\end{array}$ \\
\hline $\begin{array}{l}\text { HEALTH IMPROVEMENT } \\
\text { Surveillance and monitoring of specific } \\
\quad \text { diseases and risk factors }\end{array}$ & 73.5 & 92.9 & 19.4 & 62.5 & 65.4 \\
\hline Family/community & 70.5 & 90.6 & 20.1 & 59.0 & 67.4 \\
\hline Education & 67.0 & 91.5 & 24.5 & 47.6 & 54.9 \\
\hline Lifestyles & 66.2 & 93.0 & 26.8 & 61.9 & 68.0 \\
\hline Inequalities and social exclusion & 56.2 & 89.2 & 33.0 & 43.6 & 43.9 \\
\hline Housing and homelessness & 25.0 & 75.1 & 50.1 & 19.5 & 23.5 \\
\hline Employment & 22.6 & 65.5 & 42.9 & 24.3 & 20.4 \\
\hline $\begin{array}{l}\text { IMPROVING SERVICES } \\
\text { Clinical effectiveness }\end{array}$ & 86.1 & 96.8 & 10.7 & 66.5 & 66.9 \\
\hline Clinical governance & 85.6 & 98.1 & 12.5 & 71.3 & 70.5 \\
\hline Efficiency & 77.9 & 94.4 & 16.5 & 55.3 & 53.6 \\
\hline Service planning & 77.1 & 94.9 & 17.8 & 53.8 & 48.1 \\
\hline Audit and evaluation & 76.8 & 95.8 & 19.0 & 59.6 & 58.7 \\
\hline Equity & 68.6 & 93.9 & 25.3 & 55.3 & 50.5 \\
\hline Commissioning & 53.7 & 90.7 & 37.0 & 45.4 & 31.1 \\
\hline $\begin{array}{l}\text { HEALTH PROTECTION } \\
\text { Infectious diseases }\end{array}$ & 67.7 & 93.9 & 26.2 & 69.3 & 67.9 \\
\hline Emergency response & 44.6 & 89.7 & 45.1 & 57.0 & 52.1 \\
\hline Environmental health hazards & 23.7 & 75.5 & 51.8 & 37.7 & 33.5 \\
\hline Chemicals and poisons & 20.6 & 61.5 & 40.9 & 24.2 & 26.0 \\
\hline Radiation & 10.9 & 54.0 & 43.1 & 19.4 & 18.0 \\
\hline
\end{tabular}

